\section{Neutralizing acid rain}

\section{Eville Gorham}

ACID deposition is widely recognized as a regional environmental problem, the chief causes of which are oxides of sulphur and nitrogen emitted during fossil-fuel combustion and metal smelting. Sulphur dioxide emissions have been cut in recent years, but we have not seen matching declines in acidity of precipitation. Why the discrepancy? On page 351 of this issue, Hedin et al.${ }^{1}$ show that the deposition rate of atmospheric base cations (calcium, magnesium, potassium and sodium) has also fallen. Quite apart from its effect on acidity, the decline could adversely affect ecosystems that depend heavily on an atmospheric supply of these nutrient elements.

Acid rain was discovered in 1852 by Angus Smith, who later wrote a book on what he termed 'chemical climatology', but his work sank into obscurity. Acid precipitation was rediscovered in the mid$1950 \mathrm{~s}^{3}$ - as it happens, in three different regions. Houghton was studying cloudwater chemistry in New England. Barrett and Brodin were examining data from a network of Scandinavian stations set up to examine atmospheric inputs to agricultural ecosystems and expanded by Carl Gustav Rossby as a possible way of tracing the origins of air masses. Meanwhile, in the English Lake District I was testing the hypothesis that the ionic composition of pools on raised bogs must wholly depend on atmospheric precipitation (Einar DuRietz and Margareta Witting, whose hypothesis it was, had not actually analysed rain or snow).

Early studies (including Smith's) used a bulk collector set out continuously to catch both wet and dry deposition. A later system employed two buckets, with a cover that switched from the wet to the dry bucket during rain or snowfall. Unfortunately the dry bucket did not provide a satisfactory estimate of dry deposition, which remains very difficult to measure.

The chief impact of acid deposition upon ecosystems has been the acidification of streams and lakes bedded on rocks such as granites and quartzites, which are hard to weather and low in neutralizing bases. Aquatic floras and faunas are altered as waters acidify, often killing off fish stocks ${ }^{4}$. Deleterious effects upon terrestrial ecosystems are less clear, but may be substantial ${ }^{4}$.

Efforts to control acid deposition have focused on cutting emissions of sulphur dioxide, because sulphuric acid is a more important acidifying agent than are nitrogen oxides (once the latter have been converted to nitrate, they are rapidly absorbed by plants). Emission control has been effective, and sulphate deposition has declined sharply over the past ten to twenty years ${ }^{1}$, but without producing an equivalent reduction in precipitation acidity. In part, this could result from increasing emissions of nitrogen oxides, but Hedin et al. demonstrate that it is certainly a consequence of declining base-cation deposition.

Base cations in the atmosphere come from a range of sources ${ }^{5,6}$. Ammónia, released in increasing amounts from manures and nitrogenous fertilizers, neut-

\section{IMAGE UNAVAILABLE FOR COPYRIGHT REASONS}

Acid rain - a clouded issue.

ralizes sulphuric acid in rain and snow. But the resulting ammonium sulphate becomes an acidifying agent once it reaches the soil, owing to exchange of ammonium for hydrogen ions during root uptake and to nitrification of ammonium ions by bacteria. Fly ash from urban and industrial smokestacks is often strongly alkaline. Particles of wind-borne soil can also be alkaline, especially on calcareous bedrock, and cement dust can neutralize acid deposition locally.

In a search for causes of declining base-cation deposition, Hedin et al. consider three possibilities. Of these, they find no evidence for a decrease in atmospheric precipitation that would wash base cations less effectively from the atmosphere. Nor do they observe a decrease in windy weather that could have led to fewer soil particles being entrained into the atmosphere. What they do find, from data compiled by government agencies, are strong declines in particulate emissions from regional urban and industrial 'point sources'. Emissions of base cations from non-point sources (such as unpaved roads) are more difficult to judge, but they too may have declined ${ }^{7}$.

The significance of a decline in base- cation deposition is twofold ${ }^{1}$. First, it lessens the influence of controls on sulphur-dioxide emissions in reducing acid deposition. Second, it reduces the supply of important nutrient elements to ecosystems, some of which rely on the atmospheric supply for growth. Although nitrogen and phosphorus are the most important nutrients limiting biomass accumulation, others may become significant, particularly as atmospheric deposition of nitrogen increases ${ }^{8}$.

What, then, should be done to follow up the new results? The monitoring of basecation deposition should continue, and the other chief components of acid/base balance, ammonium and nitrate ions, should be incorporated if trends of acid $\&$ (hydrogen ion) deposition are to be understood fully. Trends in the deposition of phosphorus, often a limiting nutrient, should be examined. Soil particles are rich in this element as well as in base cations ${ }^{6}$

온 If such particles decline, phosphorus will do so. Increasing use of phosphatic fertilizers may, however, increase wind-borne phosphorus and work in the opposite direction. The few results available suggest that urban and industrial particulates are about twice as rich in phosphorus as soil particles ${ }^{9}$, so any decline in these seems likely also to be important.

This all suggests that we need to determine the importance of wind-borne soil (including road dust) relative to urban and industrial particulates. Monitoring microscopically the types of atmospheric particulates deposited on the ground would be informative, and their very different trace-element signatures ${ }^{9}$ should let them be distinguished. Seasonal examination of deposition might also help, because windborne soil ought to be least abundant during snow cover and most abundant during spring cultivation.

The irony that reducing emissions of urban and industrial particulates lessens the efficiency of sulphur-dioxide control in mitigating acid deposition will not be lost on disappointed environmentalists, who will now have to call for yet more stringent regulation of sulphur dioxide.

Eville Gorham is in the Department of Ecology and Behavioral Biology, University of Minnesota, 1987 Upper Buford Circle, Saint Paul, Minnesota 55108, USA.

1. Hedin, L. O. et al. Nature 367, 351-354 (1994)

2. Smith, R. A. Air and Rain (Longmans Green, London, 1872).

3. Cowling, E. B. Envir Sci. Technol. 16, A110-A123 (1982)

4. Nilsson, \& \& Grennfelt, P. (eds) Critical Loads for Sulphur and Nitrogen (Nordic Council of Ministers, Copenhagen, 1988).

5. Gorham, E. Geol. Soc. Am. Bull. 72, 795-840(1961).

6. Gorham, E. Water Air Soil Pollut. 6, 457-481 (1976).

7. Driscoll, C. T., Likens, G. E., Hedin, L. O., Eaton, J. S. \& Bormann, F. H. Envir. Sci. Technol. 23, 137-143(1989)

8. Schindler, D. W. \& Bayley, S. E. Global biogeochem. Cycles (in the press).

9. Rahn, K. The Chemical Composition of the Atmospheric Aerosol (Tech. Rep. Graduate School Oceanogr., Univ. Rhode Island, 1976). 